\title{
KONSTRUKSI MAKNA LOVE YOURSELF DAN MENTAL HEALTH AWARENESS BAGI ARMY (KELOMPOK PENGGEMAR BTS) TERHADAP LAGU DAN CAMPAIGN MILIK BTS
}

\author{
Attia Nabilla Yasmin, Rhae Ayu Fardani \\ UPN “Veteran” Jawa Timur
}

\begin{abstract}
Love yoursel/self-love is interpreted as a condition when we can accept and appreciate ourselves, accept our strengths and weaknesses. BTS is a Korean boy band that has managed to score international success, and is one of the bands who are diligent in voicing a campaign to ARMYs (BTS fans) about self love through an album entitled Love Yourself. The purpose of this study was to find out how ARMYs construct the meaning of Love Yourself and Mental Health Awareness of BTS songs. The method in this study is a qualitative method which aims to understand the phenomenon descriptively. The theory used to support this research is the Dialogue Theory by Carl Rogers. In this study, it is used to understand the context of the communication relationship formed from the actions and interactions of ARMY fans in interpreting self love from the Love Yourself album series by BTS.
\end{abstract}

\author{
Keywords \\ Love Yourself, Self-Love, Mental \\ Health Awareness, BTS, Meaning \\ Construction, ARMY
}

Correspondence Contact attianbll@gmail.com

\section{PENDAHULUAN}

Hallyu atau juga bisa disebut dengan Korean wave merupakan salah satu pesona yang dimiliki Korea Selatan yang banyak digandrungi oleh masyarakat kita. K-pop atau Korean Pop kini identik dengan boyband dan juga girlband. Pada beberapa waktu yang lalu, demam K-Pop dimulai dengan Super Junior, Shinee, Bigbang, SNSD, 2ne1, Wonder Girl dan masih banyak lagi. Pada saat ini K-Pop didominasi oleh K-pop generasi ketiga seperti BTS, EXO, BLACKPINK, Red Velvet, NCT dan masih banyak lagi.

BTS (akronim dari Bangtan Sonyeondan) adalah boyband Korea Selatan yang sedang berada pada puncak popularitasnya. Memulai debutnya pada Juni 2013, BTS mendapatkan pengakuan atas originalitas musiknya dan menjadi superstar global yang memecahkan banyak rekor. BTS menggunakan popularitasnya untuk menyebarkan banyak pengaruh positif, seperti kampanye Love Yourself dan pidato 'Speak Yourself' di PBB. Dengan ini, BTS masuk dalam TIME 100: The Most Influential People of 2019. Pada 2019, dalam rangka merayakan Hari Persahabatan Dunia, BTS bekerja sama dengan The United Nations Children's Fund (UNICEF) merilis video bertajuk "Love Myself". Video yang berdurasi 2 menit 29 detik ini menunjukkan rasa sakit para remaja yang menerima kekerasan, pelecehan dan bullying. Video ini menunjukkan bagaimana rasa sakit itu dapat disembuhkan melalui musik, persahabatan, dan kebaikan. Kampanye 'Love Myself' adalah kampanye yang mendorong kaum muda di seluruh dunia untuk menemukan cinta dalam diri mereka sendiri dan untuk menyebarkan cinta itu kepada orang-orang di sekitar mereka. BTS pun merilis album bertajuk 'Love Yourself: Her', 'Face Youself', 'Love Yourself: Tear', 'Love Yourself: Answer' yang mana album tersebut 
berisi lagu-lagu yang mengajak kita dan menginsiprasi kita agar kita lebih mencintai serta menghargai diri kita sendiri.

Sebelumnya, BTS juga mendapat kesempatan untuk berpidato di kantor pusat PBB. Pada pidatonya BTS mengatakan, tidak peduli siapa dirimu, darimana kamu berasal, apa warna kulitmu, apa jenis kelaminmu, kamu harus mencintai dirimu sendiri, untuk siapa dirimu, dan untuk orang yang ingin menjadi kamu. Mencintai diri sendiri adalah hal yang berbeda dengan narsis. Margaret Paul Ph.D mendefinisikan mencintai diri sendiri sebagai perilaku memahami nilai sebenarnya dalam diri, tentang apa yang sebenarnya ada di dalam diri, bukan menilai diri berdasarkan penampilan fisik atau performa diri. Mencintai diri sendiri adalah tentang penerimaan diri, penguasaan diri dan rasa hormat kepada diri sendiri.

Kurangnya mencintai diri sendiri dapat meningkatkan resio bunuh diri. Dampak rendahnya harga diri dan kurangnya mencintai diri sendiri dan kecenderungan upaya bunuh diri. Mencintai diri sendiri juga bisa didefinisikan sebagai kepercayaan diri sendiri dan keyakinan tentang bagaimana orang lain menganggap diri sendiri. Disimpulkan bahwa depresi, keputusasaan, dan harga diri yang rendah adalah implikasi dari factor kerentanan untuk keinginan bunuh diri. Maka dari itu, penting untuk mencintai diri sendiri demi mengindari halhal yang tidak diinginkan (bunuh diri)..

\section{TINJAUAN PUSTAKA}

\section{Kontruksi Makna}

a) Pengertian Konstruksi

Konstruksi dalam Kamus Besar Bahasa Indonesia, diartikan sebagai susunan (model, tata letak) suatu bangunan atau susunan dan hubungan kata dalam kelompok kata. Sedangkan menurut kamus komunikasi, definisi konstruksi adalah suatu konsep, yakni abstraksi sebagai generalisasi dari hal-hal yang khusus, yang dapat diamati dan diukur.

b) Pengertian Makna

Makna dalam Kamus Besar Bahasa Indonesia berarti arti, maksud pembicara atau penulis. Makna adalah proses aktif yang ditafsirkan seseorang dalam suatu pesan. Mead menyebutkan makna menurut perspektif interaksionisme yaitu makna interaksional dalam apa yang ia namakan suatu percakapan isyarat (conversation of gestures) dimana suatu isyarat (gesture) berarti tindakan yang bermakna secara potensial.

Makna secara interaksional dimiliki bersama dengan proses empati melalui pengambilan peran yang aktif. Individu memainkan peranan yang lebih aktif, mencari makna menurut pandangan orang lain dan dari berbagai makna itu dengan orang lain. Dengan kata lain antar individu satu dengan yang lain, makna yang dihasilkan akan berbeda sesuai dengan penafsiran masing-masing individu tersebut.

Dari penjelasan diatas, dapat ditarik kesimpulan bahwa konstruksi makna diartikan sebagai proses untuk membangun arti terhadap suatu pesan yang diterima. Dengan kata lain, konstruksi makna marupakan proses individu dalam menafsirkan sesuatu sebagai bentuk pemahamannya.

\section{Love Yourself}

Istilah love youself atau self-love memiliki kesamaan makna yaitu tentang bagaimana kita menerima dan mencintai diri sendiri. Self-love diartikan sebagai sebuah kondisi di mana kita dapat mengapresiasi diri ketika mampu bertindak ke arah yang mendukung perkembangan fisik, psikologis, dan spiritual diri. Misal mulai menerima kekurangan dan kelebihan, memiliki rasa kasih sayang terhadap diri sendiri, lebih fokus terhadap tujuan hidup yang dimiliki, serta 
hidup secara puas melalui usaha yang telah dilakukan (Khoshaba, 2012). Menurut psikolog Deborah Khoshaba Psy.D, self-love adalah keadaan apresiasi terhadap diri sendiri yang bersifat dinamis, yang tumbuh dari tindakan yang mendukung pertumbuhan fisik, psikologis, dan spiritual kita—tindakan yang membuat kita dewasa (Psychology Today, 2012).

Pernyataan tersebut menunjukan bagaimana kita sebagai tiap individu harus menerima apapun dari diri kita, berusaha menghargai diri sendiri dari segala aspek yang ada pada dalam diri kita, yang terlihat maupun tidak terlihat. Dari pengertian para ahli yang sudah dijelaskan, dapat diambil kesimpulan bahwa self love/love yourself merupakan suatu keadaan dimana kita sebagai individu dapat menerima segala aspek yang ada dalam diri kita, aspek positif maupun negative, aspek yang terlihat maupun tidak terlihat. Dan juga keadaan dimana kita dapat mengapresiasi diri sendiri atas semua hal yang telah dilakuka.

\section{Mental Health Awareness}

Federasi Kesehatan Mental Dunia (World Federation for Mental Health) merumuskan pengertian kesehatan mental sebagai kondisi yang memungkinkan adanya perkembangan yang optimal baik secara fisik, intelektual dan emosional, sepanjang hal itu sesuai dengan keadaan orang lain. Sebuah masyarakat yang sehat secara mental adalah masyarakat yang membolehkan anggota masyarakatnya berkembang sesuai kemampuannya. Mental Health Awareness merupakan bentuk kesadaran kita akan kesehatan mental diri kita maupun orang lain. Mental Health Awareness juga menjadi salah satu faktor utama dalam menciptakan lingkungan yang terbuka dan positif yang dapat menyelamatkan banyak kehidupan orang lain di luar sana.

\section{Pemahaman Diri}

Teori Dialog oleh Carl Rogers dalam penelitian ini digunakan untuk memahami konteks hubungan komunikasi yang terbentuk dari tindakan dan interaksi penggemar ARMY dalam memaknai self love dari series album Love Yourself oleh BTS. Rogers menghasilkan teori tentang komunikasi dan memberikan garis pedoman bagaimana berkomunikasi dengan lebih efektif dalam hubungan. Pendekatan Rogers dianggap normatif atau preskriptif dan sering disebut 'teori diri' atau self karena pendekatan Rogers banyak membahas hubungan seperti membahas tentang diri karena diri tidak dapat dipisahkan dari hubungan. (Littlejohn, 2009: 310).

Rogers mengungkapkan, ketika cara yang anda gunakan untuk berubah sesuai dengan pengalaman, anda akan mengalami harmoni. Sebaliknya, jika keduanya bertentangan maka anda akan mengalami tidak harmoni. (Littlejohn, 2009: 310-311). Dalam penelitian ini, penggemar remaja ARMY menemukan pemahaman tentang dirinya melalui self love dari BTS dan lagu dalam series album Love Yourself yang diaplikasikannya ke pengalaman komunikasinya dalam melakukan tindakan self love. Dalam pengalaman tersebut akan dilihat apakah penggemar ARMY mengalami harmoni atau tidak harmoni dan bagaimana mereka mempersepsikan maknai self love dalam dirinya.

\section{METODOLOGI}

Jenis penelitian ini adalah kualitatif dengan tujuan memahami fenomena secara deskriptif. Alan Bryman dalam buku Social Research Method (2012) mengatakan bahwa, berbeda dengan penelitian kuantitatif yang mengadopsi model ilmiah alami, penelitian kualitatif lebih menekankan kepada dunia sosial melalui interpretasi sebuah dunia oleh respondennya. Metode penelitian yang digunakan adalah wawancara. Wawancara adalah salah satu metode penelitian yang paling sering digunakan. Wawancara cenderung lebih fleksibel, merespon ke 
arah mana responden menjawab pertanyaan dan memungkinkan untuk menyesuaikan penekanan terhadap masalah yang akan diteliti.

\section{HASIL DAN PEMBAHASAN}

\section{Pengalaman ARMY (Kelompok Penggemar BTS) Surabaya Mengenai Campaign Milik BTS.}

Setiap orang di dunia ini memiliki pengalaman baik dan juga buruk. Biasanya kedua hal tersebut cenderung dijadikan acuan bagi setiap individu untuk berkembang. Beberapa ARMY mengaku bahwa memiliki banyak kesulitan yang umumnya dirasakan oleh kebanyakan remaja saat ini, namun ada juga yang mengalami kesulitan yang tidak biasa dan terbilang cukup berat untuk dijalani sendiri. ARMY merasa dengan adanya group penggemar ini, mereka lebih memiliki dukungan lebih dan dengan adanya lagu-lagu BTS mereka merasa terwakili serta memiliki motivasi untuk selalu bangkit, terutama lagu-lagu BTS yang bertema tentang Love Yourself. Dimulai dengan adanya BTS yang memberikan pidatonya di UNICEF yang berisi tentang rasa sakit para remaja yang menerima kekerasan, pelecehan serta bullying. Pidato tersebut ditujukan untuk membuktikan bahwa bagaimana rasa sakit itu dapat disembuhkan melalui musik, persahabatan, dan kebaikan.

Pengalaman buruk yang dimiliki ARMY tersebut yang menyebabkan mereka terdorong untuk melakukan healing dengan cara mengaplikasikan pesan Love Yourself yang disampaikan BTS lewat pidato dan lagu-lagu mereka. Setelah BTS mendeklarasi campaign dengan sang leader RM mengatakan "No matter who you are, where you're from, your skin color, your gender identity, just speak yourself. Find your name and find your voice by speaking yourself.", seluruh ARMY di seluruh dunia berbondong-bondong untuk mengajak dan menyebarkan kegiatan yang berisi tentang pesan-pesan Love Yourself yang pada akhirnya menjadi suatu campaign besar yang masih dilanjutkan oleh para ARMY sampai dengan sekarang. Pentingnya mental health awareness pada akhirnya mulai tergagas dan terus menerus dijadikan patokan dalam setiap kegiatan para ARMY dan juga BTS. Pada akhirnya pengalaman baik pun terbentuk dengan adanya pengalaman buruk itu tadi.

\section{Konstruksi Makna Love Yourself dan Mental Health Awareness Bagi ARMY (Kelompok Penggemar BTS) Terhadap Lagu dan Campaign Milik BTS.}

Musik merupakan media komunikasi bagi para penyanyi untuk menyampaikan pesan pada para pendengar dan penggemarnya. Pendengar musik juga diharapkan mulai peduli dengan lirik dan pesan yang ingin disampaikan oleh penyanyi serta memaknai pesan dari dalam lagu tersebut. Berdasarkan pengalaman yang dirasakan oleh mereka, ajakan demi ajakan dan kegiatan demi kegiatan yang bertema Love Yourself kian ramai, akhirnya banyak orang-orang yang mulai bergabung dengan komunitas ARMY karena campaign tersebut. Mereka beranggapan bahwa dengan bergabung menjadi ARMY akan memberikan dampak positif dan mereka senang ikut turut serta meamaikan dan melaksanakan campaign milik BTS dan saling menguatkan satu sama dengan yang lainnya.

Makna yang didapatkan oleh mereka adalah campaign dan lagu-lagu milik BTS ini ditujukan untuk menghargai diri kita sendiri, dari hasil konstruksi makna tersebut, ARMY menjadikan Love Yourself sebagai jalan untuk menerima diri sendiri dan lebih menghargai diri sendiri serta apa yang ia miliki dikehidupannya. Mereka juga memaknai Love Yourself untuk menikmati hidup dan membuat mereka lebih menikmati momen yang mereka miliki dan jalani agar lebih bahagia. Love Yourself juga dimaknai mereka sebagai acuan untuk lebih percaya diri tidak peduli mereka terlahir dari keluarga seperti apa, lingkungan seperti apa, warna kulit apa dan apapun itu agar mereka dapat menemukan jati diri mereka serta lebih menerima kekurangan serta kelebihan yang mereka. Terakhir, mereka memaknai Love Yourself untuk 
memotivasi mereka dalam mencapai mimpi dan cita cita mereka, terus berusaha untuk menggapai apa yang mereka inginkan dan terus melakukan hal-hal positif yang mereka suka tanpa harus mendengarkan ejekan dan terus membuktikan bahwa diri mereka memang pantas.

Dengan adanya komunitas ARMY, mereka mereka yang tertindas merasa memiliki dukungan lebih dan perlindungan sebagai penguat mereka. Setiap mereka merasa down, mereka akan terus mendengarkan lagu milik BTS dan memaknai pesan-pesan didalamnya. Tidak jarang pula para ARMY ini melakukan gathering/pertemuan rutin yang biasanya diadakan ketika ada event tertentu seperti ulangtahun anggota BTS, hari jadi BTS dan momen comeback BTS. Hal tersebut dimanfaatkan mereka untuk saling bertukar pikiran, bercerita tentang keluh kesah mereka dan saling support satu sama lain dengan memberikan saran maupun sekadar mendengarkan karena sejatinya seorang manusia itu butuh didengarkan.

\section{KESIMPULAN}

BTS sebagai boyband asal korea yang sudah mendunia dan memiliki penggemar terbanyak mampu memiliki campaign yang cukup besar. ARMY sebagai penggemar BTS pun turut memeriahkan campaign tersebut dan campaign tersebut telah mempengaruhi banyak orang dari kalangan manapun tak terkecuali non ARMY yang pada akhirnya ikut bergabung menjadi penggemar BTS. Pengalaman buruk yang mereka miliki mendorong mereka untuk ikut kedalam campaign tersebut yang pada akhirnya mewujudkan pengalaman baik dan campaign ini terus berjalan untuk mengajak semua kalangan agar menerapkan Love Yourself dan gencar terhadap Mental Health Awareness. Makna dari Love Yourself dan Mental Health Awareness sendiri sangat dipahami dan dimaknai dengan baik oleh ARMY sebagaimana apa yang diharapkan oleh kebanyakan orang pada akhirnya, kesehatan mental dapat dimengerti dengan baik dengan cara mencintai diri sendiri terlebih dahulu dan menerima semua yang ada dihidup kita

\section{DAFTAR PUSTAKA}

Anggi Putra, Ilham, M.Psi.2019. Self-Love: Apa Dan Bagaimana?. Kariib.com https://kariib.com/self-love-apa-dan-bagaimana/

Anwar, Rosalyn Citra. 2018. Mahasiswa dan K-Pop (Studi Interaksi Simbolik K-Popers di Makassar). Jurnal Ilmu Komunikasi UPN Veteran Jatim No 1 Vol. 1. Surabaya.

Beck, Bhar, Brown \& Ghahramanlou-Holloway (2008). "Self-Esteem and Suicide Ideation in Psychiatric Outpatients". Suicide and Life-Threatening Behavior 38.

Bryman, Alan. 2012. Social Research Methods. Oxford University Press, Inc. New York.

Deby Subandi, Fadelia. 2018. Self Love : on Forgiving Te Self. Bempsikologi.ui.ac.id. https://bempsikologi.ui.ac.id/2018/10/05/self-love-on-forgiving-the-self/

Doro, Nabila. 2019. Pentingnya pemahaman \& kesadaran soal kesehatan mental di Indonesia. Brilio.net https://www.brilio.net/creator/pentingnya-pemahaman-kesadaran-soalkesehatan-mental-di-indonesia-b60ca5.html

Ika, Nuraini. 2019. Hari Persahabatan Sedunia: BTS \& UNICEF Rilis Kampanye LOVE MYSELF. Tirto.id https://tirto.id/hari-persahabatan-sedunia-bts-unicef-rilis-kampanye-lovemyself-efhv 
Yasmin. A.N, Fardani. R.A Konstruksi Makna Love Yourself Dan Mental Health Awareness Bagi Army

(Kelompok Penggemar BTS) Terhadap Lagu Dan Campaign Milik BTS

Purnamasari, Deti Mega. 2018. Tampil di PBB, Begini Isi Pidato Inspiratif BTS. Jawapos.com https://www.jawapos.com/entertainment/25/09/2018/tampil-di-pbb-begini-isipidato-inspiratif-bts/

Putra, Awan Rachmad (2014). BAB 11 KAJIAN TEORITIS. KONSTRUKSI MAKNA GOYANG CAISAR DI KALANGAN.... http://digilib.uinsby.ac.id/ 